\title{
Antibiotic Susceptibility profile of Staphylococcus aureus isolated from sausages in Meknes, Morocco
}

\author{
Abdelaziz Ed-Dra ${ }^{1}$, Fouzia Rhazi Filali ${ }^{1}$, Aziz Bouymajane ${ }^{1}$, Faouzia Benhallam ${ }^{1}$, Abdellah El Allaoui ${ }^{1}$, Abdellah Chaiba $^{2}$ and \\ Filippo Giarratana ${ }^{3}$
}

1. Team of Microbiology and Health, Laboratory of Chemistry-Biology Applied to the Environment, Moulay Ismail University Faculty of Science, BP. 11201 Zitoune Meknes, Morocco; 2. SADS-CRMEF Souss Massa Daraa Inezgane, Agadir, Morocco; 3. Department of Veterinary Science, University of Messina, Polo Universitario della Annunziata, 98168 Messina, Italy.

Corresponding author: Abdelaziz Ed-Dra, e-mail: abdelaziz_iaa@yahoo.fr

Co-authors: FRF: fouzia.filali@yahoo.fr, AB: azizbouymajane.01@gmail.com,FB: f_benhallam@hotmail.com, AEA: alaouixsaraa@hotmail.com, AC: abchaiba@yahoo.fr, FG: fgiarratana@unime.it Received: 10-06-2018, Accepted: 16-08-2018, Published online: 19-10-2018

doi: 10.14202/vetworld.2018.1459-1465 How to cite this article: Ed-Dra A, Rhazi Filali F, Bouymajane A, Benhallam F, El Allaoui A, Chaiba A, Giarratana F (2018) Antibiotic Susceptibility profile of Staphylococcus aureus isolated from sausages in Meknes, Morocco, Veterinary World, 11(10): 1459-1465.

\begin{abstract}
Background and Aims: Staphylococcus aureus is one of the most common causes of foodborne disease worldwide, due to the consumption of food contaminated by their toxins. This study aimed to determine the prevalence and the antimicrobial resistance of $S$. aureus isolated from sausages in Meknes city of Morocco.
\end{abstract}

Materials and Methods: A total of 156 samples (Beef sausages, Turkey sausages, and Artisanal sausages "Merguez") were collected from different shopping sites (butchery, supermarket, street vendors, and weekly market "Souk") and used for the isolation of $S$. aureus. All the isolated strains were tested for their antimicrobials resistance to 16 antibiotics.

Results: Our results showed the presence of $S$. aureus in 63 samples (40.38\%). Furthermore, the antimicrobial resistance study showed that $84.13 \%$ of isolated $S$. aureus were resistant to streptomycin, $76.20 \%$ to tetracycline, $42.86 \%$ to ampicillin, $41.27 \%$ to doxycycline, $38.1 \%$ to penicillin $\mathrm{G}$, and $19.05 \%$ to chloramphenicol with the presence of 25 different phenotypic profiles. However, all isolated strains were sensitive to oxacillin, cefoxitin, gentamicin, and vancomycin.

Conclusion: The findings of this study revealed consumption of sausages as a potential risk of foodborne poisonings because of its contamination with the multi-resistant strains of $S$. aureus. Moreover, this contamination is related to the season, sampling sites and the origin of the raw material.

Keywords: antimicrobial resistance, foodborne disease, infection, sausages, Staphylococcus aureus.

\section{Introduction}

Foodborne diseases are a major public health concern worldwide and are defined as a disease of infectious or toxic nature caused by, or thought to be caused by, the consumption of contaminated food or water [1]. Staphylococcal foodborne disease is one of the most frequent universal foodborne diseases, and it is caused by the ingestion of food contaminated with enterotoxins produced by some strains of Staphylococcus [2,3]. Its symptoms have a rapid onset (2-6 h) and may include vomiting, stomach pain, and diarrhea [4].

The genus Staphylococcus is placed in the family Micrococcaceae. This genus is divided into coagulase-positive staphylococci and coagulase-negative staphylococci based on their ability to coagulate plasma [5]. Staphylococcus aureus is the most

Copyright: Ed-Dra, et al. Open Access. This article is distributed under the terms of the Creative Commons Attribution 4.0 International License (http://creativecommons.org/licenses/ by/4.0/), which permits unrestricted use, distribution, and reproduction in any medium, provided you give appropriate credit to the original author(s) and the source, provide a link to the Creative Commons license, and indicate if changes were made. The Creative Commons Public Domain Dedication waiver (http:// creativecommons.org/publicdomain/zero/1.0/) applies to the data made available in this article, unless otherwise stated. significant human pathogen among the staphylococci. It is a ubiquitous spherical bacterium, Grampositive and facultative anaerobic. He can grow in a wide range of $\mathrm{pH}$ (between 4.2 and 9.3), temperatures (between $7^{\circ} \mathrm{C}$ and $48.5^{\circ} \mathrm{C}$ ), and in a high concentration of sodium chloride (15\%) [1]. These characteristics favor the growth of this bacterium in many food products. Indeed, previous studies have isolated $S$. aureus from various food of animal origin [6-12].

Worldwide, $S$. aureus is considered the third common pathogen that causes food poisoning [13]. In the United States, S. aureus is considered one of the top five pathogens causing domestically acquired foodborne diseases and is responsible for an estimate of 241,000 illnesses per year [10,14]. In 2009, 23 cases of food poisoning were reported in France due to the consumption of raw milk and cheese contaminated with $S$. aureus [15]. A study in Morocco showed that $S$. aureus was responsible for $72 \%$ of foodborne outbreaks [16]. Moreover, the delegation of epidemiology and disease control reported 13,339 cases of foodborne diseases between 2001 and 2010 of which $31 \%$ were caused by $S$. aureus [17].

The extended use and misuse of antibiotics in agriculture, stock farming, veterinary medicine, and 
treatment of human diseases increase the resistance of bacteria to antimicrobial agents. In livestock farms, different antimicrobial agents are used extensively in sub-therapeutic/therapeutic doses for growth promotion, routine disease prevention, and treatment of bacterial diseases $[18,19]$. This indiscriminate practice is usually worse in developing countries including Morocco, where there are no strict controls on the use of antimicrobials in food-producing animals [20]. This has led to increased resistance to different antimicrobials used in these fields [11,21-23]. In the last years, $S$. aureus resistant to methicillin (MRSA) and vancomycin (VRSA) was isolated from different samples $[1,7,8,10,21,23-26]$, these antibiotics are a choice drug for the treatment of cases infected by this bacterium; hence, the World Health Organization has triggered the alarm signal about these resistances and ranked the MRSA and VRSA among the high priority for searching the new and effective antibiotic treatments [27].

In this context, this study aimed to evaluate the prevalence of $S$. aureus in sausages sold in Meknes city (Morocco) and to determine the antimicrobial susceptibility of isolated strains.

\section{Materials and Methods}

\section{Ethical approval}

Ethical approval was not required in this study since no live animals were used in the experiments.

\section{Samples collection and microbiological analysis}

A total of 156 samples of sausages distributed as follow: 60 of turkey sausages, 60 of beef sausages, and 36 of "Merguez" sausages were randomly colket, butcheries, and street vendors. The collection was carried out during 1 year from March 2014 to February 2015. The samples were aseptically collected, and each sample was placed in a separate, sterile plastic bag. The samples were brought under refrigeration to the laboratory and analyzed within the following $2 \mathrm{~h}$. The samples $(25 \mathrm{~g})$ were weighed into sterile stomacher bags diluted with $225 \mathrm{~mL}$ sterile buffered peptone water (Biokar) and homogenized in a stomacher for about $1 \mathrm{~min}$; $0.1 \mathrm{~mL}$ was streaked on Baird-Parker (BP) agar (Biokar) supplemented with egg yolk tellurite emulsion and incubated at $37^{\circ} \mathrm{C}$ for $24-48 \mathrm{~h}$. Strains cultured on BP agar medium were identified as $S$. aureus if growth was observed and the colonies showed the typical morphologic characteristics (black colonies with an opaque precipitation halo). The tube coagulate test was determined and evaluated for coagulation after 3 and 24 h of incubation.

\section{Antibiotic susceptibility}

The resistance pattern of $S$. aureus was determined using the disk-diffusion test [28]. 16 antibiotics (Oxoid) were chosen for the study based on the most used active principles in human medicine, national veterinary therapy, and according to their common use lected from various local supermarkets, weekly mar-

in research. The use of oxacillin/methicillin is not usually used in veterinary practice, and it was included in this study only for epidemiological purposes; the drugs tested are indicated in Table-1. Multiple antibiotic resistance (MAR) index is calculated as the ratio of some resistance antibiotics to the total number of antibiotics to which the isolates are exposed. S. aureus ATCC 29213 was used as a control strain.

\section{Statistical analysis}

The data were presented as means \pm standard error, and the statistical analyses were performed using Microsoft Office Excel (2010). The comparison of contamination averages was performed using the student test with $\mathrm{p}<0.05$.

\section{Results}

\section{Contamination rate of sausages by staphylococci}

This study was carried out during 1 year to evaluate the contamination level of sausages by staphylococci, and to study the effect of the different factors influencing this contamination. The results of this study show that the average rate of contamination with staphylococci was $3.42 \pm 0.88 \mathrm{log} \mathrm{cfu} / \mathrm{g}$ with a minimum value of $1.47 \mathrm{log} \mathrm{cfu} / \mathrm{g}$ and a maximum value of $5.6 \mathrm{log} \mathrm{cfu} / \mathrm{g}$. The study of seasonal effect shows that staphylococci take a maximum value during autumn (4.15 $\pm 0.86 \log \mathrm{cfu} / \mathrm{g})$, followed by summer (3.68 $\pm 0.78 \log \mathrm{cfu} / \mathrm{g})$, winter $(3.00 \pm 0.46 \log \mathrm{cfu} / \mathrm{g})$, and spring $(2.90 \pm 0.71 \mathrm{log} \mathrm{cfu} / \mathrm{g})$ (Figure-1), with a significant difference between the cold seasons (winter and spring) and the hot seasons (autumn and summer $)(p<0.05)$. Furthermore, the study of the sampling sites effect shows that sausages sold at street vendors are the most contaminated with staphylococci (3.82 $\pm 0.84 \mathrm{log} \mathrm{cfu} / \mathrm{g})$, followed by souk (3.6 $\pm 0.61 \mathrm{log} \mathrm{cfu} / \mathrm{g})$, butchery $(3.5 \pm 0.88 \mathrm{log} \mathrm{cfu} / \mathrm{g})$, and the supermarket $(2.51 \pm 0.46 \mathrm{log} \mathrm{cfu} / \mathrm{g})$ (Figure-2), while the sausages sold in supermarket differ significantly from those sold in the others sites $(p<0.05)$. In the other hand, the result of this study showed that

Table-1: Antimicrobial agents and the range of concentrations tested.

\begin{tabular}{llc}
\hline Antimicrobial agents & Code & $\begin{array}{c}\text { Concentration } \\
\text { disc }(\boldsymbol{\mu g})\end{array}$ \\
\hline Penicillin G & P & 6 \\
Ampicillin & AMP & 10 \\
Oxacillin & OX & 5 \\
Cefoxitin & FOX & 30 \\
Gentamicin & GN & 30 \\
Kanamycin & K & 30 \\
Fusidic acid & FD & 10 \\
Ofloxacin & OFX & 5 \\
Enrofloxacin & ENR & 5 \\
Erythromycin & E & 15 \\
Tetracycline & TE & 30 \\
Doxycycline & DXT & 30 \\
Vancomycin & VA & 30 \\
Chloramphenicol & C & 30 \\
Streptomycin & S & 10 \\
Trimethoprim-sulfamethoxazole & SXT & $1.25 / 23.75$ \\
\hline
\end{tabular}


the raw material origin has a significant effect on the contamination rate of sausages by staphylococci $(p<0.05)$; the artisanal sausages "Merguez" is the most contaminated $(3.82 \pm 0.84 \mathrm{log} \mathrm{cfu} / \mathrm{g})$, followed by beef sausages $(3.5 \pm 0.93 \log \mathrm{cfu} / \mathrm{g})$ and turkey sausages (3.15 $\pm 0.75 \mathrm{log} \mathrm{cfu} / \mathrm{g})$ (Figure-3).

\section{Prevalence of $S$. aureus in sausage samples}

The isolation and identification of $S$. aureus were performed according to the method described previously. From 156 analyzed samples, 63 were positive for $S$. aureus $(40.38 \%)$. These results showed that $S$. aureus governs the summer season (Table-2);

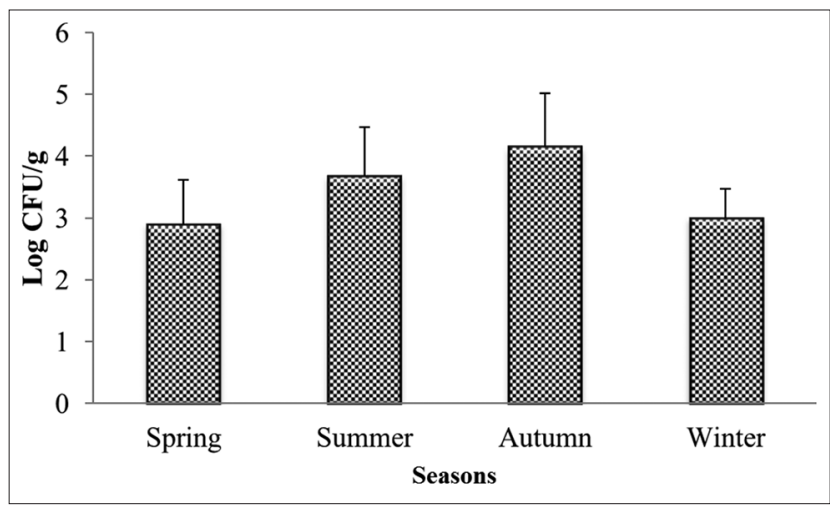

Figure-1: The average values of staphylococci counted in sausages according to seasons sampling.

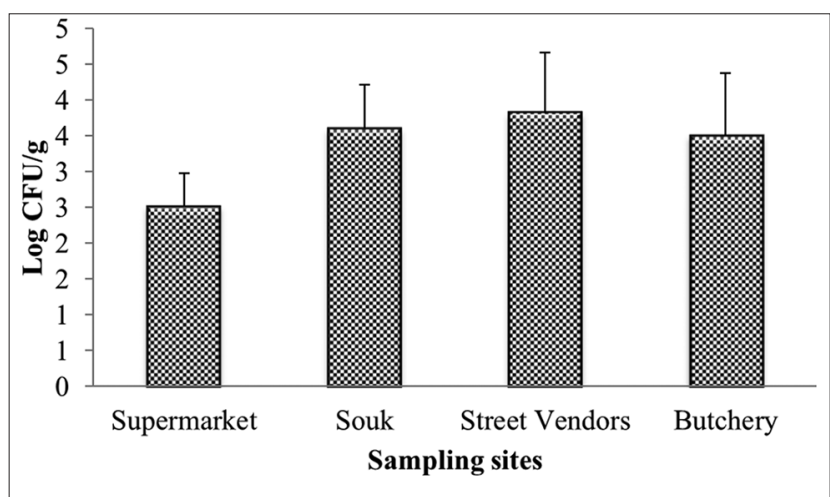

Figure-2: The average values of staphylococci counted in sausages according to sampling sites.

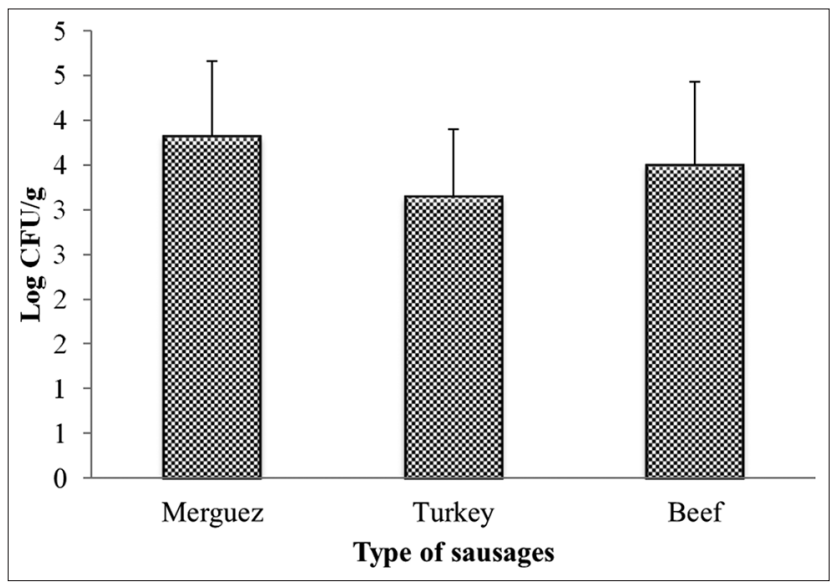

Figure-3: The average values of staphylococci counted in sausages according to sausages types. furthermore, the study of sampling sites effect showed that the sausages sold in street vendors were the most contaminated with 50\% (Table-3). On the other hand, the artisanal sausages "Merguez" was the most contaminated with $S$. aureus according to the raw material origin (Table-4).

\section{Antibiotic susceptibility test}

The antibiotic susceptibly was carried out according to the method described by the Clinical Laboratory Standard Institute. The isolated $S$. aureus (63) was tested for 16 antibiotics belonging to different groups, and the results are presented in Table-5. This results showed that 61 isolates $(96.82 \%)$ were resistant to at least one antibiotic, $56(88.88 \%)$ were resistant to two or more antibiotics, and $44(69.84 \%)$ were resistant to three or more antibiotics (considered as Multi-resistant). Moreover, the analysis of our results showed that the MAR index varies between 0 and 0.56 with the presence of 25 different phenotypic profiles (Table-6).

Among the tested antibiotics, the isolated strains were resistant to streptomycin $(84.13 \%)$, followed by tetracycline $(76.20 \%)$, ampicillin $(42.86 \%)$, doxycycline (41.27\%), and penicillin G (38.1\%). On the other hand, they were sensitive to oxacillin, cefoxitin, gentamicin, and vancomycin (Table-5).

Table-2: Effect of sampling seasons on sausages contamination with $S$. aureus.

\begin{tabular}{lccc}
\hline Sampling & \multicolumn{3}{c}{ Number of samples } \\
\cline { 2 - 4 } seasons & Analyzes & Positives & Percentage \\
\hline Spring & 39 & 16 & 41.02 \\
Summer & 39 & 29 & 74.36 \\
Autumn & 39 & 14 & 35.89 \\
Winter & 39 & 4 & 10.25 \\
\hline
\end{tabular}

S. aureus=Staphylococcus aureus

Table-3: Effect of sampling sites on sausages contamination with $S$. aureus.

\begin{tabular}{lccc}
\hline Sampling sites & \multicolumn{3}{c}{ Number of samples } \\
\cline { 2 - 4 } & Analyzes & Positives & Percentage \\
\hline Butchery & 72 & 28 & 38.88 \\
Supermarket & 24 & 3 & 12.5 \\
Street vendors & 36 & 18 & 50 \\
Weekly market & 24 & 14 & 58.33 \\
\hline
\end{tabular}

S. aureus=Staphylococcus aureus

Table-4: Effect of raw material origin on sausages contamination with $S$. aureus.

\begin{tabular}{lccc}
\hline Origin & \multicolumn{3}{c}{ Number of samples } \\
\cline { 2 - 4 } & Analyzes & Positives & Percentage \\
\hline Turkey sausage & 60 & 22 & 36.66 \\
Beef sausage & 60 & 23 & 38.33 \\
Artisanal sausages & 36 & 18 & 50 \\
"Merguez" & \multicolumn{3}{l}{} \\
\hline \multicolumn{2}{l}{ S. aureus=Staphylococcus aureus } \\
\hline
\end{tabular}


Table-5: Antimicrobial resistance percentages of isolated $S$. aureus.

\begin{tabular}{llcc}
\hline Antibiotics & & \multicolumn{2}{c}{ Number of S. aureus isolates (n=63) } \\
\cline { 2 - 4 } & & S (\%) & R (\%) \\
\hline Penicillin $\mathrm{G}(6 \mu \mathrm{g})$ & $\mathrm{P}$ & $39(61.9)$ & $24(38.1)$ \\
Ampicillin $(10 \mu \mathrm{g})$ & AMP & $36(57.14)$ & $27(42.86)$ \\
Oxacillin $(5 \mu \mathrm{g})$ & OX & $63(100)$ & $0(0)$ \\
Cefoxitin $(30 \mu \mathrm{g})$ & FOX & $63(100)$ & $0(0)$ \\
Gentamicin $(30 \mu \mathrm{g})$ & CN & $63(100)$ & $0(0)$ \\
Kanamycin $(30 \mu \mathrm{g})$ & K & $59(93.65)$ & $4(6.35)$ \\
Fusidic acid $(10 \mu \mathrm{g})$ & FD & $62(98.41)$ & $1(1.59)$ \\
Ofloxacin $(5 \mu \mathrm{g})$ & OFX & $54(85.71)$ & $9(14.29)$ \\
Enrofloxacin $(5 \mu \mathrm{g})$ & ENR & $54(85.71)$ & $9(14.29)$ \\
Erythromycin $(15 \mu \mathrm{g})$ & E & $60(95.24)$ & $3(4.76)$ \\
Tetracycline $(30 \mu \mathrm{g})$ & TE & $15(23.80)$ & $48(76.20)$ \\
Doxycycline $(30 \mu \mathrm{g})$ & DXT & $37(58.73)$ & $26(41.27)$ \\
Vancomycin $(30 \mu \mathrm{g})$ & VA & $63(100)$ & $0(0)$ \\
Chloramphenicol $(30 \mu \mathrm{g})$ & C & $51(80.95)$ & $12(19.05)$ \\
Streptomycin $(10 \mu \mathrm{g})$ & S & $10(15.87)$ & $53(84.13)$ \\
Trimethoprim-sulfamethoxazole $(1.25 \mu \mathrm{g} / 23.75 \mu \mathrm{g})$ & SXT & $61(96.82)$ & $2(3.18)$ \\
\hline S. & & &
\end{tabular}

S. aureus=Staphylococcus aureus

Table-6: Resistance profile of isolated S. aureus.

\begin{tabular}{|c|c|c|c|}
\hline Number of antibiotics & Resistance profile & Number of Isolates & MAR \\
\hline 0 & & 2 & 0 \\
\hline \multirow[t]{2}{*}{1} & TE & 4 & 0.06 \\
\hline & $\mathrm{S}$ & 1 & 0.06 \\
\hline \multirow[t]{4}{*}{2} & $\mathrm{~S}, \mathrm{TE}$ & 9 & 0.125 \\
\hline & $\mathrm{TE}, \mathrm{C}$ & 1 & 0.125 \\
\hline & OFX, ENR & 1 & 0.125 \\
\hline & S, AMP & 1 & 0.125 \\
\hline \multirow[t]{4}{*}{3} & $\mathrm{~S}, \mathrm{AMP}, \mathrm{P}$ & 9 & 0.19 \\
\hline & S, TE, DXT & 6 & 0.19 \\
\hline & $\mathrm{S}, \mathrm{TE}, \mathrm{C}$ & 2 & 0.19 \\
\hline & $\mathrm{S}, \mathrm{TE}, \mathrm{SXT}$ & 1 & 0.19 \\
\hline \multirow[t]{3}{*}{4} & $\mathrm{~S}, \mathrm{TE}, \mathrm{DXT}, \mathrm{C}$ & 4 & 0.25 \\
\hline & S, TE, DXT, SXT & 1 & 0.25 \\
\hline & $\mathrm{S}, \mathrm{TE}, \mathrm{OFX}, \mathrm{ENR}$ & 1 & 0.25 \\
\hline \multirow[t]{7}{*}{5} & $\mathrm{~S}, \mathrm{TE}, \mathrm{DXT}, \mathrm{AMP}, \mathrm{P}$ & 7 & 0.31 \\
\hline & $\mathrm{S}, \mathrm{TE}, \mathrm{DXT}, \mathrm{C}, \mathrm{P}$ & 2 & 0.31 \\
\hline & $\mathrm{S}, \mathrm{AMP}, \mathrm{OFX}, \mathrm{ENR}, \mathrm{K}$ & 1 & 0.31 \\
\hline & $\mathrm{TE}, \mathrm{DXT}, \mathrm{AMP}, \mathrm{P}, \mathrm{E}$ & 1 & 0.31 \\
\hline & TE, DXT, OFX, ENR, E & 1 & 0.31 \\
\hline & $\mathrm{S}, \mathrm{TE}, \mathrm{DXT}, \mathrm{C}, \mathrm{FD}$ & 1 & 0.31 \\
\hline & $\mathrm{S}, \mathrm{TE}, \mathrm{DXT}, \mathrm{AMP}, \mathrm{C}$ & 1 & 0.31 \\
\hline \multirow[t]{2}{*}{6} & $\mathrm{~S}, \mathrm{TE}, \mathrm{AMP}, \mathrm{P}, \mathrm{ENR}, \mathrm{OFX}$ & 2 & 0.37 \\
\hline & $\mathrm{S}, \mathrm{TE}, \mathrm{DXT}, \mathrm{AMP}, \mathrm{P}, \mathrm{K}$ & 1 & 0.37 \\
\hline 7 & $\mathrm{~S}, \mathrm{TE}, \mathrm{AMP}, \mathrm{P}, \mathrm{OFX}, \mathrm{ENR}, \mathrm{K}$ & 2 & 0.43 \\
\hline 9 & $\mathrm{~S}, \mathrm{TE}, \mathrm{DXT}, \mathrm{AMP}, \mathrm{P}, \mathrm{C}, \mathrm{OFX}, \mathrm{ENR}, \mathrm{E}$ & 1 & 0.56 \\
\hline
\end{tabular}

MAR=Multiple antibiotic resistance index, $S=$ Streptomycin, TE=Tetracycline, AMP=Ampicillin, $P=$ Penicillin $G$, $\mathrm{C}=$ Chloramphenicol, OFX=Ofloxacin, ENR=Enrofloxacin, $\mathrm{K}=$ Kanamycin, $\mathrm{E}=$ Erythromycin, $\mathrm{DXT}=$ Doxycycline, FD=Fusidic acid, SXT=Trimethoprim-Sulfamethoxazole. $S$. aureus=Staphylococcus aureus

\section{Discussion}

The genus Staphylococcus includes at least 40 species which are pathogenic bacteria causing a broad spectrum of diseases with varying degrees of severity; their natural habitat includes humans, animals, and environment. The presence of staphylococci in food is considered a major risk to the public health, for this reason, its limit of acceptability in sausages was fixed at $5.10^{3} \mathrm{cfu} / \mathrm{g}$ in Morocco.

The results of our study showed that the contamination rate of sausages with staphylococci has an average rate of $3.42 \pm 0.88 \mathrm{log} \mathrm{cfu} / \mathrm{g}$ with a minimum of $1.47 \mathrm{log} \mathrm{cfu} / \mathrm{g}$ and a maximum of $5.6 \mathrm{log} \mathrm{cfu} / \mathrm{g}$, of which $31.41 \%$ exceeds the limit and are unfit for consumption. These results are similar to those found in Turkey [29], lower than those reported in Nigeria [30], and higher than the results carried out in Jordan [31]. However, a study carried out previously in Rabat city (Morocco) showed that the contamination of poultry meat with staphylococci has an average rate of $2.67 \mathrm{log} \mathrm{cfu} / \mathrm{g}$ [32].

Our finding showed the presence of $S$. aureus in 63 samples $(40.38 \%)$. These results are similar 
to that found in the imported meats in South Korea (40.94\%) [15] and fresh sausages samples in Egypt (45\%) [33]. They are higher than that reported in poultry meat in Rabat city of Morocco (16.66\%) [32], chicken samples in China (24.2\%) [23], analyzed meat samples in Italy (10\%) [34], and fresh meat samples in Shanghai (28.1\%) [35]. However, they are lower than that reported in turkey samples in the USA (64.2\%) [10]. In Italy, the results published by Pesavento et al. [6] showed the presence of $S$. aureus in $23.86 \%$ of analyzed samples, with $28.57 \%$ in poultry meat, $29.41 \%$ in beef meat, and $15.15 \%$ in pork meat. The high contamination of sausages with $S$. aureus may occur directly from contaminated raw material or may results from poor hygiene during production processes or at the retail and storage stage [36].

The massive use of antibiotics in feed to promote growth and the inappropriate use of antimicrobials agents in veterinary and human medicine are considered to be major contributors to the emergences of resistance [20,37]. Moreover, S. aureus is notorious for its ability to become resistant to antimicrobials due to their capacity to produce an exopolysaccharide barrier and because of their location within microabscesses, which limit the action of drugs [38]. In the other hand, the acquisition of resistance genes by horizontal transfer has high importance; some studies prove the presence of different genes such as tet $M$, mecA, and blaZ that are responsible for the resistance to tetracycline, oxacillin, and penicillin, respectively [39].

The results of our study showed that $96.82 \%$ of isolated $S$. aureus were resistant to at least one antibiotic, $88.88 \%$ were resistant to two or more antibiotics, and $69.84 \%$ were resistant to three or more antibiotics. A study in Italy showed that $68.8 \%$ of analyzed S. aureus were resistant to at least one antibiotic [34]. In Jordan, about $88.5 \%$ of the $S$. aureus exhibited resistance to at least one antibiotic in imported fresh fish samples [40]. In the United States, $52 \%$ of the $S$. aureus isolated from meat and poultry samples were multi-resistant [19].

The antimicrobial analysis showed that $84.13 \%$ of isolated $S$. aureus are resistant to streptomycin, this result is higher than that found in retail chicken in Egypt $(52.1 \%)$ [41], and in food samples in Iran (5.8\%) [39]. Furthermore, $76.20 \%$ of isolated strains were resistant to tetracycline; this result is similar to that found in retail chicken in Egypt taking in consideration the intermediate and resistance profiles [41], but higher than that found in Italy (19.04\%) [6], Jordan (36.5\%) [39], and Iran (29.6\%) [42].

The rate of resistance to ampicillin and penicillin $\mathrm{G}$ was $42.86 \%$ and $38.1 \%$, respectively. The resistance to these antibiotics is common in $S$. aureus and has been observed previously in Malaysia $(72.30 \%$ ampicillin and 53.38\% penicillin) [43], Iran (77.3\% ampicillin and $76 \%$ penicillin G) [44], and Italy $(42.86 \%$ ampicillin and $16.66 \%$ penicillin $G$ ) [6]. On the other hand, the isolated strains of $S$. aureus were sensitive to gentamicin, oxacillin, cefoxitin, and vancomycin.
The high percentage of resistant $S$. aureus isolates to these antibiotics could be due to the widespread administration of these antimicrobials to control and treat infections on dairy farms [39]. Furthermore, MAR index analysis showed the presence of 25 different phenotypic profiles among the 63 strains. This diversity can be explained by the different sources of contamination of sausages since the preparation of the raw material (slaughter, evisceration, cutting) until the manufacturing, storage, and sales in different sites $[36,45]$.

\section{Conclusion}

The high level of contamination of sausages with $S$. aureus highlights the poor hygiene all along the chain of manufacture and sale of this product. Furthermore, our study showed that the consumption of this product might be a potential risk of foodborne infection. Fortunately, we have not found strains resistant to methicillin and vancomycin, but this resistance can be acquired from the medical or veterinary fields to the food chain product. Hence, it is interesting to survey the resistance profile of this bacterium in all the stage manufacturing process and applied the good practices of hygiene and Hazard Analysis Critical Control Point especially in informal sales sites.

\section{Authors' Contributions}

This work was carried out in collaboration between all authors. AE, FRF, and FB designed the experimental procedures. $\mathrm{AE}, \mathrm{AB}, \mathrm{AEA}$, and $\mathrm{AC}$ conducted the experimental analysis. AE, FRF, and FG analyzed the data and wrote the manuscript. All authors read and approved the final manuscript.

\section{Acknowledgments}

The authors thank the members of the regional laboratory of epidemiological diagnosis and environmental hygiene of Meknes-Tafilalet Region for the help in sampling and microbiological analysis. The authors declare that they did not receive any funding source to support this study.

\section{Competing Interests}

The authors declare that they have no competing interests.

\section{References}

1. Le Loir, Y., Baron, F. and Gautier, M. (2003) Staphylococcus aureus and food poisoning. Genet. Mol. Res., 2(1): 63-76.

2. Lima, G.C., Loiko, M.R., Casarin, L.S. and Tondo, E.C. (2013) Assessing the epidemiological data of Staphylococcus aureus food poisoning occurred in the State of Rio Grande do Sul, Southern Brazil. Braz. J. Microbiol., 44(3): 759-763.

3. Saadat, Y.R., Fooladi, A.A.I., Shapouri, R., Hosseini, M.M. and Khiabani, Z.D. (2014) Prevalence of enterotoxigenic Staphylococcus aureus in organic milk and cheese in Tabriz, Iran. Iran. J. Microbiol., 6(5): 345-349.

4. Jørgensen, H.J., Mørk, T., Caugant, D.A., Kearns, A. and Rørvik, L.M. (2005) Genetic variation among Staphylococcus aureus strains from Norwegian bulk milk. Appl. Environ. Microbiol., 71(12): 8352-8361. 
5. Pyorala, S. and Taponen, S. (2009) Coagulase-negative staphylococci emerging mastitis pathogens. Vet. Microbiol., 134: 3-8.

6. Pesavento, G., Ducci, B., Comodo, N., Nostro, A.L. (2007) Antimicrobial resistance profile of Staphylococcus aureus isolated from raw meat: A research for methicillin-resistant Staphylococcus aureus (MRSA). Food Control, 18(3): 196-200

7. Pereira, V., Lopes, C., Castro, A., Silva, J., Gibbs, P. and Teixeira, P. (2009) Characterization for enterotoxin production, virulence factors, and antibiotic susceptibility of Staphylococcus aureus isolates from various foods in Portugal. Food Microbiol., 26(3): 278-282.

8. Can, H.Y. and Celik, T.H. (2012) Detection of enterotoxigenic and antimicrobial resistant $S$. aureus in Turkish cheeses. Food Control, 24(1): 100-103.

9. Abdellah, E., Fouzia, R.F. and Bouchra, O. (2013) Prevalence and antibiogram study of Escherichia coli and Staphylococcus aureus in turkey meat in Morocco. Pharm. Anal. Acta., 4: 270.

10. Abdalrahman, L.S., Stanley, A., Wells, H. and Fakhr, M.K. (2015) Isolation, virulence, and antimicrobial resistance of methicillin-resistant Staphylococcus aureus (MRSA) and methicillin sensitive Staphylococcus aureus (MSSA) strains from Oklahoma retail poultry meats. Int. J. Environ. Res. Public Health, 12(6): 6148-6161.

11. Kim, Y.J., Oh, D.H., Song, B.R., Heo, E.J., Lim, J.S., Moon, J.S., Park, H.J., Wee, S.W. and Sung, K. (2015) Molecular characterization, antibiotic resistance, and virulence factors of methicillin-resistant Staphylococcus aureus strains isolated from imported and domestic meat in Korea. Foodborne Pathog. Dis., 12(5): 390-398.

12. Osman, K.M., Amer, A.M., Badr, J.M. and Saad, A.S. (2015) Prevalence and antimicrobial resistance profile of Staphylococcus species in chicken and beef raw meat in Egypt. Foodborne Pathog. Dis., 12(5): 406-413.

13. Zhang, S., Iandolo, J.J. and Stewart, G.C. (1998) The enterotoxin D plasmid of Staphylococcus aureus encodes a second enterotoxin determinant (sej). FEMS. Microbiol. Lett., 168: 227-233.

14. Scallan, E., Hoekstra, R.M., Angulo, F.J., Tauxe, R.V., Widdowson, M.A., Roy, S.L. and Griffin, P.M. (2011) Foodborne illness acquired in the United States-major pathogens. Emerg. Infect. Dis., 17(1): 7-15.

15. Ostyn, A., De Buyser, M.L., Guillier, F., Groult, J., Felix, B., Salah, S., Delmas, G. and Hennekinne, J.A. (2010) First evidence of a food poisoning outbreak due to staphylococcal enterotoxin type E, France, 2009. Eurosurveillance, 15(13): 1-4.

16. Belomaria, M., Ahami, A.O.T., Aboussaleh, Y., Elbouhali, B., Cherrah, Y. and Soulaymani, A. (2007) Environmental origin of collective foodborne diseases in Morocco: Case of the Gharb Chrarda Bni Hssen region. Antropo, 14: 83-88.

17. Directorate of Epidemiology and Disease Control. (2011) Epidemiology of Food Poisoning in Morocco: A Retrospective Study Over Ten Years (2001-2010). Rabat, Morocco.

18. Gilchrist, M.J., Greko, C., Wallinga, D.B., Beran, G.W., Riley, D.G. and Thorne, P.S. (2007) The potential role of concentrated animal feeding operations in infectious disease epidemics and antibiotic resistance. Environ. Health Perspect., 115: 313-316.

19. Waters, A.E., Contente-Cuomo, T., Buchhagen, J., Liu, C.M., Watson, L., Pearce, K., Foster, J.T., Bowers, J., Driebe, E.M., Engelthaler, D.M., Keim, P.S. and Price, L.B. (2011) Multidrug-resistant Staphylococcus aureus in US meat and poultry. Clin. Infect. Dis., 52(10): 1227-1230.

20. Ed-dra, A., Rhazi, F.F., Karraouan, B., El Allaoui, A., Aboulkacem, A. and Bouchrif, B. (2017) Prevalence, molecular and antimicrobial resistance of Salmonella isolated from sausages in Meknes, Morocco. Microb. Pathog.,
105: $340-345$.

21. De Boer, E., Zwartkruis-Nahuis, J.T.M., Wit, B., Huijsdens, X.W., De Neeling, A.J., Bosch, T., Van Oosterom, R.A.A., Vila, A. and Heuvelink, A.E. (2009) Prevalence of methicillin-resistant Staphylococcus aureus in meat. Int. J. Food Microbiol., 134(1-2): 52-56.

22. Kluytmans, J.A. (2010) Methicillin-resistant Staphylococcus aureus in food products: Cause for concern or case for complacency? Clin. Microbiol. Infect., 16(1): 11-15.

23. Wang, X., Tao, X., Xia, X., Yang, B., Xi, M., Meng, J., Zhang, J. and Xu, B. (2013) Staphylococcus aureus and methicillin-resistant Staphylococcus aureus in retail raw chicken in China. Food Control, 29(1): 103-106.

24. European Food Safety Authority. (2009) Analysis of the baseline survey on the prevalence of methicillin-resistant Staphylococcus aureus (MRSA) in holdings with breeding pigs, in the EU, 2008, Part A: MRSA prevalence estimates; on request from the European Commission. EFSA Journal, 7(11): 1376 .

25. Campbell, J.A., Dickson, J.S., Cordray, J.C., Olson, D.G., Mendonca, A.F. and Prusa, K.J. (2014) Survival of methicillin-resistant Staphylococcus aureus during thermal processing of frankfurters, summer sausage, and ham. Foodborne Pathog. Dis., 11(1): 50-54.

26. Azim, S., Nimmo, G.R. and McLaws, M.L. (2015) Meticillin-resistant Staphylococcus aureus (MRSA) antibiogram: How inaccurate have our estimates been?. J. Glob. Antimicrob. Resist., 3(2): 80-84.

27. World Health Organization. (2017) Global Priority List of Antibiotic-Resistant Bacteria to Guide Research, Discovery, and Development of New Antibiotics. World Health Organization, Geneva.

28. Clinical and Laboratory Standards Institute. (2014) Performance Standards for Antimicrobial Susceptibility Testing: Twenty-fourth Informational Supplement, M100-S24. Clinical and Laboratory Standards Institute, Wayne, PA.

29. Siriken, B., Cadirci, O., Inat, G., Yenisey, C., Serter, M. and Ozdemir, M. (2009) Some microbiological and physicochemical quality of Turkish Sucuk (Sausage). J. Anim. Vet. $A d v$, 8: 2027-2032.

30. Oluwafemi, F. and Simisaye, M.T. (2006) Extent of microbial contamination of sausages sold in two Nigerian cities. Afr. J. Biomed. Res., 9: 133-136.

31. Ayman, S.M., Jihad, M.Q., Nizar, I.A. and Omer, T.M.E. (2013) The quality of Jordanian sausage products stored at $4^{\circ} \mathrm{C}$. Agric. J., 8: 115-118.

32. Khallaf, M., Benbakhta, B., Nasri, I., Sarhane, B., Senouci, S. and Ennaji, M.M. (2014) Prevalence of Staphylococcus aureus isolated from chicken meat marketed in Rabat, Morocco. Int. J. Inn. Appl. Stud., 7(4): 1665-1670.

33. Tarabees, R.Z., Hassanin, Z.H., Sakr, M.A. and Zidan, S.A. (2016) Molecular screening of some virulence factors associated with Staphylococcus aureus isolated from some meat products. Alexandria J. Vet. Sci., 48(1): 12-19.

34. Normanno, G., La Salandra, G., Dambrosio, A., Quaglia, N.C., Corrente, M., Parisi, A., Santagada, G., Firinu, A., Crisetti, E. and Celano, G.V. (2007) Occurrence, characterization and antimicrobial resistance of enterotoxigenic Staphylococcus aureus isolated from meat and dairy products. Int. J. Food Microbiol., 115(3): 290-296.

35. Song, M., Bai, Y., Xu, J., Carter, M.Q., Shi, C. and Shi, X. (2015) Genetic diversity and virulence potential of Staphylococcus aureus isolates from raw and processed food commodities in Shanghai. Int. J. Food Microbiol., 195: 1-8.

36. Ed-dra, A., Rhazi, F.F., El Allaoui, A. and Aboulkacem, A. (2017) Factors influencing the bacteriological quality of sausages sold in Meknes city, Morocco. Int. Food Res. J., 24(3): 933-938.

37. Oniciuc, E.A., Nicolau, A.I., Hernández, M. and RodríguezLázaro, D. (2017) Presence of methicillin-resistant 
Staphylococcus aureus in the food chain. Trends Food Sci. Technol., 61: 49-59.

38. Gündoğan, N., Citak, S. and Turan, E. (2006) Slime production, DNase activity and antibiotic resistance of Staphylococcus aureus isolated from raw milk, pasteurised milk and ice cream samples. Food Control, 17(5): 389-392.

39. Jamali, H., Paydar, M., Radmehr, B., Ismail, S. and Dadrasnia, A. (2015) Prevalence and antimicrobial resistance of Staphylococcus aureus isolated from raw milk and dairy products. Food Control, 54: 383-388.

40. Obaidat, M.M., Bani, S.A.E., Lafi, S.Q. (2015) Prevalence of Staphylococcus aureus in imported fish and correlations between antibiotic resistance and enterotoxigenicity. J. Food Prot., 78(11): 1999-2005.

41. Sallam, K.I., Abd-Elghany, S.M., Elhadidy, M. and Tamura, T. (2015) Molecular characterization and antimicrobial resistance profile of methicillin-resistant Staphylococcus aureus in retail chicken. J. Food Prot., 78(10): 1879-1884.

42. Mashouf, R.Y., Hosseini, S.M., Mousavi, S.M. and Arabestani, M.R. (2015) Prevalence of enterotoxin genes and antibacterial susceptibility pattern of Staphylococcus aureus strains isolated from animal originated foods in West of Iran. Oman Med. J., 30(4): 283-290.

43. Tan, S.L., Lee, H.Y. and Mahyudin, N.A. (2014) Antimicrobial resistance of Escherichia coli and Staphylococcus aureus isolated from food handler's hands. Food Control, 44: 203-207.

44. Dallal, M.M.S., Foroushani, A.R., Sharifi-Yazdi, S., Sharifi-Yazdi, M.K. and Arfatahery, N. (2015) Prevalence of Staphylococcus aureus in Shrimps in Tehran during 2013. J. Med. Bacteriol., 4(5-6): 42-46.

45. Ed-Dra, A., Filali, F.R., El Allaoui, A. and Sfendla, A. (2017) Occurrence of Clostridium perfringens in sausages sold in Meknes city, Morocco. Open Vet. J., 7(4): 323-327.

$* * * * * * * *$ 